Article

\title{
Time-Resolved Spectroscopic Study of $N, N$-Di(4-bromo)nitrenium Ions in Selected Solutions
}

\author{
Lili Du ${ }^{1,2,+}{ }^{-}$, Xin Lan ${ }^{1,+}{ }^{-}$, Zhiping Yan ${ }^{1}$, Ruixue Zhu ${ }^{1,3}$ and David Lee Phillips ${ }^{1, *(\mathbb{C}}$ \\ 1 Department of Chemistry, The University of Hong Kong, Hong Kong S.A.R., China; \\ justailleen@gmail.com (L.D.); xinlan@connect.hku.hk (X.L.); mcayzp@gmail.com (Z.Y.); \\ zhurx@shanghaitech.edu.cn (R.Z.) \\ 2 Institute of Life Sciences, Jiangsu University, Zhenjiang 212013, China \\ 3 School of Physical Science and Technology, Shanghai Tech University, Shanghai 201210, China \\ * Correspondence: phillips@hku.hk; Tel.: +852-2859-2160 \\ + These authors contributed equally to this work.
}

Academic Editor: Chong Fang

Received: 8 November 2018; Accepted: 30 November 2018; Published: 3 December 2018

\begin{abstract}
Nitrenium ions are important reactive intermediates in chemistry and biology. In this work, femtosecond and nanosecond transient absorption (fs-TA and ns-TA) along with nanosecond time-resolved resonance Raman (ns- $\mathrm{TR}^{3}$ ) experiments were employed to examine the photochemical pathways of $\mathrm{N}$-(4,4'-dibromodiphenylamino)-2,4,6-trimethylpyridinium $\mathrm{BF}_{4}{ }^{-}$(salt (DN) from just absorption of a photon of light to the production of the important $N, N$-di(4-bromophenyl)nitrenium ion 2. In acetonitrile $(\mathrm{MeCN})$, the formation of halogenated diarylnitrenium ion $\mathbf{2}$ was observed within $4 \mathrm{ps}$, showing the vibrational spectra with strong intensity. The nucleophilic adduct reaction of ion 2 with $\mathrm{H}_{2} \mathrm{O}$ was also examined in aqueous solutions. The direct detection of the unique ortho adduct intermediate 3 shows that there is an efficient and exclusive reaction pathway for 2 with $\mathrm{H}_{2} \mathrm{O}$. The results shown in this paper give new characterization of 2 , which can be used to design time-resolved spectroscopy investigations of covalent addition reactions of nitrenium ions with other molecules in future studies.
\end{abstract}

Keywords: nitrenium ion; resonance Raman; transient absorption; reactive intermediate

\section{Introduction}

Nitrenium ions are important intermediates which structurally have a formal positive charge on the nitrogen. Many research works have shown that aryl nitrenium ions have mutagenic properties in chemical carcinogenesis of aromatic amines [1-9].<smiles>CN(c1ccccc1)c1ccccc1</smiles>

1<smiles>C[N+](C)(c1ccc(Br)cc1)c1ccc(Br)cc1</smiles>

2

Scheme 1. The structures of nitrenium ions.

Falvey and coworkers [10-13] reported several works on the chemical and spectroscopic behavior of the $N, N$-diphenylnitrenium ion (1) formed after photoexcitation of the 1-(N,N-dipheylamino)-2,4,6-triphenylpyridinium ion (see Scheme 1), and this aryl nitrenium 
ion was proven to have a ground state singlet character with some overlap between an unfilled nitrogen based $p$-orbital with filled $\pi$-orbitals on the phenyl groups $[12,14]$. Furthermore, Thomas and Falvey's research work showed that the $N, N$-di(4-bromophenyl)nitrenium ion (2) formed after photoexcitation of $N$-(4, $4^{\prime}$-dibromodiphenylamino)-2,4,6-trimethylpyridinium $\mathrm{BF}_{4}^{-}$salt (DN) had greater stability with a longer lifetime than the unsubstituted nitrenium ion $\mathbf{1}$, which was revealed by study of laser flash photolysis to have a lifetime of $124 \mu \mathrm{s}$ in $\mathrm{MeCN}$, and $6.57 \mu$ s in water [10]. Macernis et al., studied the effect of surrounding polar environments on the molecular behavior of the related nitrogen [15]. Even though the differing decay pathways of halogenated diarylnitrenium ion 2 in organic and aqueous solutions were predicted in some research as shown in Scheme 2, the reaction mechanisms of 2 remained unclear due to the lack of direct evidence regarding their structure and properties of the relevant intermediates [10].<smiles>Cc1cc(C)[n+](-c2ccc(Br)cc2)c(C)c1</smiles>

DN

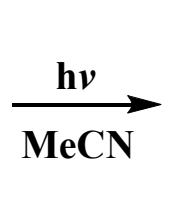

$\mathrm{Br}$<smiles></smiles><smiles>Brc1ccccc1</smiles><smiles>Cc1cc(C)nc(C)c1</smiles>

2<smiles>Oc1cc(Br)ccc1NCCCSCCNc1ccc(Br)cc1</smiles>

4

Scheme 2. Reaction mechanism for photoexcitation of $N$-(4,4'-dibromodiphenylamino)-2,4,6trimethylpyridinium $\mathrm{BF}_{4}{ }^{-}$salt $(\mathrm{DN})$ proposed by Falvey and coworkers [10].

In this paper, femtosecond transient absorption (fs-TA) was utilized to directly investigate the photo-induced formation of halogenated diarylnitrenium ion 2. In addition, the structures and characteristics of 2 were characterized with nanosecond time-resolved resonance Raman $\left(n s-\mathrm{TR}^{3}\right.$ ) spectroscopy experiments, and these results are probably the first time-resolved vibrational spectroscopic characterization of the halogenated diarylnitrenium ion 2 . Furthermore, nanosecond transient absorption (ns-TA) and ns-TR ${ }^{3}$ experiments were employed to examine the behavior of 2 in near neutral aqueous solution, and these results provide new insight into the structure and chemical reactivity of 2 in aqueous solutions. 


\section{Results and Discussion}

\subsection{In $\mathrm{MeCN}$}
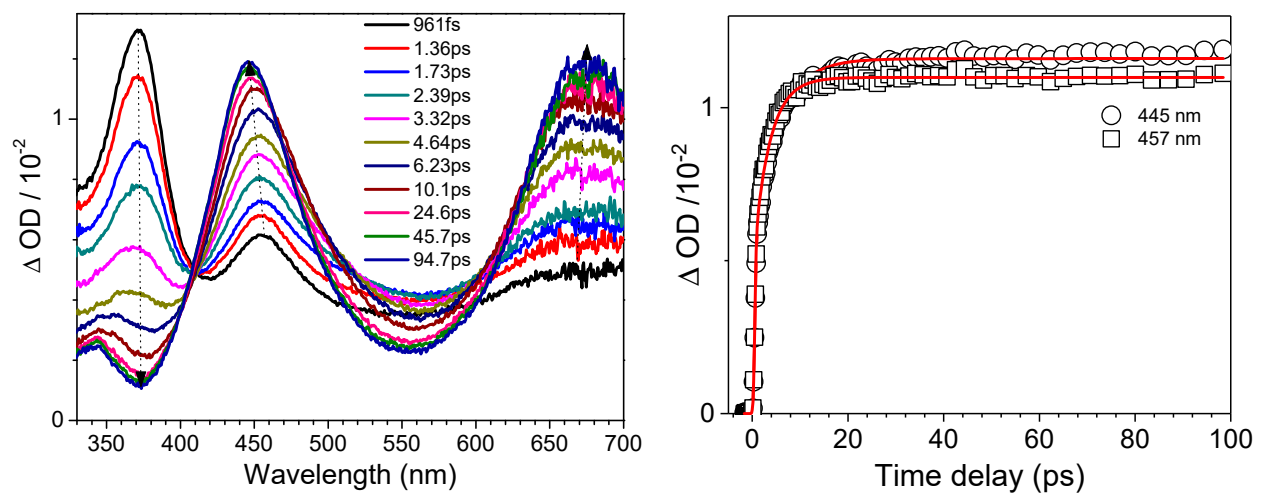

Figure 1. Displayed are femtosecond transient absorption (fs-TA) spectra of DN in acetonitrile (MeCN) acquired after $267 \mathrm{~nm}$ irradiation (left), and kinetics of the band at $445 \mathrm{~nm}$ and $457 \mathrm{~nm}$ (right).

Figure 1 displays the fs-TA spectra of $\mathrm{DN}$ in $\mathrm{MeCN}$, and the early time spectra appearing at $370 \mathrm{~nm}$ and $457 \mathrm{~nm}$ may be attributed to the transient absorption of DN in its lowest excited singlet state. Later, the feature at $370 \mathrm{~nm}$ decreases in intensity significantly, with the $457 \mathrm{~nm}$ feature increasing in intensity and blue-shifting to $445 \mathrm{~nm}$ up to about $94.7 \mathrm{ps}$. Concurrently, the broad feature peaking at $675 \mathrm{~nm}$ appears and reaches its intensity maximum around $100 \mathrm{ps}$. The spectral variation from $1 \mathrm{ps}$ to 100 ps can be attributed to indicate the generation of 2 , subsequent to photo-cleavage of the $\mathrm{N}-\mathrm{N}$ bond, because it was also observed in nanosecond laser flash photolysis [10]. As displayed in the right of Figure 1, the decay kinetics of the absorption band at $445 \mathrm{~nm}$ and $457 \mathrm{~nm}$ can be modeled well with a one-exponential function with a 4.3 ps time constant. Thus, the DN excited singlet state decay and the generation of 2 can be determined to be $4.3 \mathrm{ps}$, with one species evolving into the other, as evidenced by the isobestic points seen in the fs-TA data. Comparison of these results to those for the growth time constant obtained for generation of the 2-fluorenyl nitrenium ion (167 ps) [16] indicates the faster photo-cleavage seen for DN results in much faster generation of $\mathbf{2}$, which accompanied by its high yield, suggests this photochemical method for formation of $\mathbf{2}$ has good promise in investigating the reactions of $\mathbf{2}$ with nucleosides and other substrate molecules.

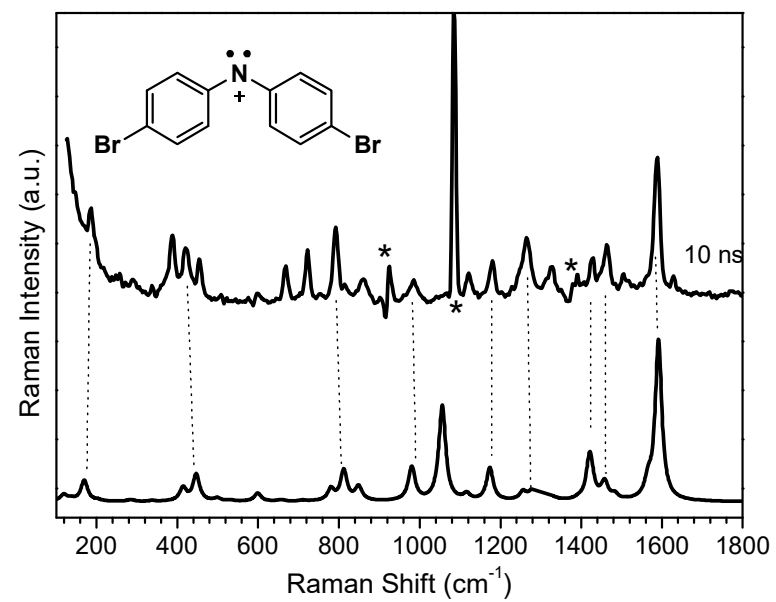

Figure 2. Comparison of the nanosecond time-resolved resonance Raman (ns-TR ${ }^{3}$ ) 10 ns spectrum obtained after excitation of $\mathrm{DN}$ in $\mathrm{MeCN}$ (pump $266 \mathrm{~nm}$, probe $416 \mathrm{~nm}$ ) to the density functional theory (DFT) calculated normal Raman spectrum of $\mathbf{2}$. The symbol * means features affected by solvent subtraction artifacts. 
So as to better understand the vibrational structural information and characteristics of $\mathbf{2}, \mathrm{ns}^{-\mathrm{TR}^{3}}$ experiments were performed for $\mathrm{DN}$ in $\mathrm{MeCN}$ by using $266 \mathrm{~nm}$ for the photolysis and $416 \mathrm{~nm}$ for the wavelength of the probe. Figure S2 presents the ns-TR ${ }^{3}$ spectra obtained after photoexcitation of DN in $\mathrm{MeCN}$ from $10 \mathrm{~ns}$ up to $300 \mu \mathrm{s}$, and during this time region, mostly one intermediate was seen and its long lifetime is consistent with the literature value of the lifetime of 2, found by Falvey and coworkers from their ns-TA study (124 $\mu \mathrm{s})$ [10]. Density functional theory (DFT) computations were used to simulate the normal Raman spectrum of $\mathbf{2}$, and comparison with the experimental $\mathrm{TR}^{3}$ spectrum is given in Figure 2. It can be seen that the predicted normal Raman spectrum for the nitrenium ion 2 agrees well with the $10 \mathrm{~ns}$ experimental $\mathrm{TR}^{3}$ spectrum based on comparison of the patterns of the vibrational frequencies. The small differences between the relative Raman intensities of the computed and experimental spectra could be due to the resonance enhancement for the experimental Raman spectra, whereas the computed one is a normal Raman spectrum without the resonance effect. There are several strong Raman features at $1589,1463,1264,812,447$, and $169 \mathrm{~cm}^{-1}$ seen in the $\mathrm{TR}^{3}$ spectra, and those located at 1589,1463 , and $1264 \mathrm{~cm}^{-1}$ can mostly be attributed to $C=C$ stretching vibrational modes of the phenyl rings. The $812 \mathrm{~cm}^{-1}$ Raman feature may be attributed to the $\mathrm{H}-\mathrm{C}-\mathrm{C}-\mathrm{H}$ wagging vibrational modes. The features at $447 \mathrm{~cm}^{-1}$ and $169 \mathrm{~cm}^{-1}$ may be connected with the $\mathrm{C}-\mathrm{N}-\mathrm{C}$ bending mode and the $\mathrm{C}-\mathrm{Br}$ stretching mode. The computations suggest the $\mathrm{C}-\mathrm{N}$ stretching feature is located near $1371 \mathrm{~cm}^{-1}$ that is consistent with Falvey and colleagues literature report for the diphenylnitrenium ion 1 using TR-IR spectra [17]. Unfortunately, the strong Raman MeCN feature at $1372 \mathrm{~cm}^{-1}$ obscures the $\mathrm{C}-\mathrm{N}$ stretching feature by solvent subtraction. It is interesting to note the differences between 2 and 1 by comparing their DFT computed normal Raman spectra in Figure S3. By correcting by the same scaling factor, the vibrational mode for the stretching of the diphenyl rings of $\mathbf{1}$ also shows the feature at $1589 \mathrm{~cm}^{-1}$ is the same as that for 2 . Intriguingly, the intensities of Raman features in the $200-1500 \mathrm{~cm}^{-1}$ region for the halogenated 2 intermediate have much greater relative intensity compared to the non-halogenated 1 intermediate that may be due to the halogen electronic effect on the in-plane $\mathrm{C}-\mathrm{H}$ bending vibrations [18]. Thus, the 2 intermediate may be thought of being a better nitrenium ion for observing nucleophilic reactions with some nucleosides by utilizing ns-TR ${ }^{3}$ spectroscopy [9].

\subsection{In Aqueous Solution}

Falvey and coworkers found that the nucleophilic reaction of 2 with $\mathrm{H}_{2} \mathrm{O}$ was first order in terms of the $\left[\mathrm{H}_{2} \mathrm{O}\right]$, and measured a $1.12 \times 10^{4} \mathrm{M}^{-1} \mathrm{~s}^{-1}$ second order rate constant [10]. In comparison to the very high chemical reactivity of the DNA bases $[6,9,10]$, the longer lifetime and lower chemical reactivity of 2 toward $\mathrm{H}_{2} \mathrm{O}$ enables the ability to determine the lifetimes and chemical reactivity of 2 and similar nitrenium ions in aqueous environments. Thus, the spectroscopic investigation in aqueous media may be useful information when planning for further investigations of the reactions of $\mathbf{2}$ with other molecules in the future.

The fs-TA spectra obtained after photoexcitation of DN in an aqueous solution are also shown in Figure S4, which were essentially the same as those seen in MeCN. The time constant for the formation of 2 in aqueous solution is also about 4 ps, which is very similar to that observed in $\mathrm{MeCN}$. In addition, Figure 3 displays the ns-TA spectra obtained after photoexcitation of DN in aqueous solution. As the absorption features at $450 \mathrm{~nm}$ and $680 \mathrm{~nm}$ decay, the feature at $340 \mathrm{~nm}$ increases in intensity within about $9.4 \mu \mathrm{s}$. Because the para position of 2 is obstructed by bromine in comparison to $\mathbf{1}$, one would expect the nucleophilic reaction to take place at the ortho positon of $\mathbf{2}$, as seen in Scheme 2 [10]. Thus, the increasing intensity in the feature at $340 \mathrm{~nm}$ may be attributed to the formation of ortho adduct intermediate 3 after nucleophile addition or the final product 4 . 


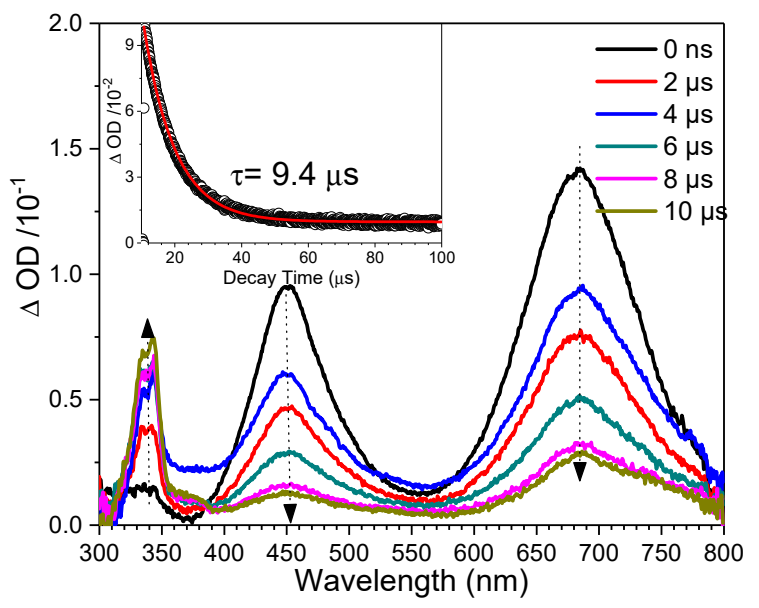

Figure 3. Shown are ns-TA spectra obtained in a 1:1 MeCN: $\mathrm{H}_{2} \mathrm{O}$ solution after $266 \mathrm{~nm}$ irradiation of DN. The kinetics at $450 \mathrm{~nm}$ appear in the insert.

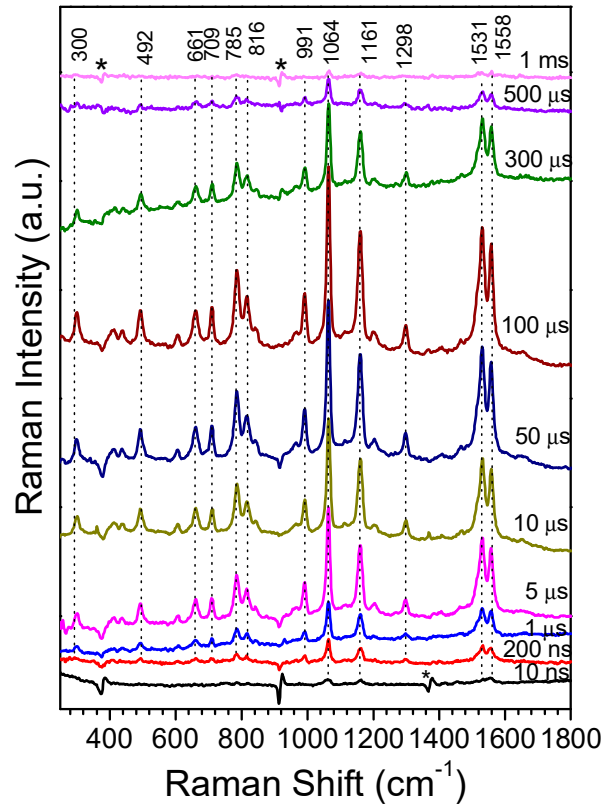

Figure 4. Shown are the $\mathrm{ns}-\mathrm{TR}^{3}$ spectra using a $341.5 \mathrm{~nm}$ probe wavelength for intermediates formed after $266 \mathrm{~nm}$ photoexcitation of $\mathrm{DN}$ in a 1:1 MeCN: $\mathrm{H}_{2} \mathrm{O}$. The star symbols mark places influenced by solvent subtraction artifacts.

Ns-TR ${ }^{3}$ experiments were done to ascertain the vibrational properties of the involved intermediates in aqueous solution by using a probe laser wavelength of $341.5 \mathrm{~nm}$ and a $266 \mathrm{~nm}$ pump wavelength. According to the ns-TA spectra for intermediates observed after photoexcitation of $\mathrm{DN}$ in aqueous solution, the absorption features at $450 \mathrm{~nm}$ and $680 \mathrm{~nm}$ decay while the feature at $340 \mathrm{~nm}$ increases, which indicates that a new species is observed in aqueous solution that could be more easily detected by the $\mathrm{ns}-\mathrm{TR}^{3}$ with a probe wavelength in the $300 \mathrm{~nm}$ to $370 \mathrm{~nm}$ region, and we thus selected $341.5 \mathrm{~nm}$ as a convenient probe wavelength to use from our experimental set-up. Figure 4 shows the ns-TR ${ }^{3}$ spectra obtained from $10 \mathrm{~ns}$ to $1 \mathrm{~ms}$ after $266 \mathrm{~nm}$ excitation of $\mathrm{DN}$ in a 1:1 MeCN: $\mathrm{H}_{2} \mathrm{O}$ solution. Inspection of Figure 4 shows a new species appears at $10 \mathrm{~ns}$ and reaches a maximum intensity near $100 \mu \mathrm{s}$, then decays over the next $900 \mu \mathrm{s}$. Figure 5 displays a comparison of the $100 \mu \mathrm{s}$ $\mathrm{ns}-\mathrm{TR}^{3}$ spectrum to the DFT predicted normal Raman spectrum of intermediate 3 and product 4 that clearly shows the computed vibrational frequencies and Raman intensities for intermediate 3 agree better with the experimental ns-TR ${ }^{3}$ spectrum vibrational frequency patterns. Thus, the longer lifetime 
intermediate seen in aqueous solution may be attributed to intermediate 3 . This assignment is in agreement with the mechanism proposed by Falvey and coworkers [10], and importantly gives a direct piece of evidence for the existence of nucleophilic adduct reaction intermediate 3 formed by reaction of 2 with $\mathrm{H}_{2} \mathrm{O}$. There are six strong Raman features, at 1558, 1531, 1298, 1161, 1064, and $785 \mathrm{~cm}^{-1}$, seen in the ns-TR ${ }^{3}$ spectrum of $\mathrm{DN}$ in the aqueous solution. The features at 1558 and $1531 \mathrm{~cm}^{-1}$ can mostly be attributed to $\mathrm{C}=\mathrm{N}$ and $\mathrm{C}=\mathrm{C}$ stretching vibrational modes. The $1298 \mathrm{~cm}^{-1}$ Raman feature can be attributed to the $\mathrm{O}-\mathrm{H}$ rocking vibrational modes. The bands at $1161 \mathrm{~cm}^{-1}$, $1064 \mathrm{~cm}^{-1}$, and $785 \mathrm{~cm}^{-1}$ can be connected with the $\mathrm{C}-\mathrm{H}$ wagging modes.

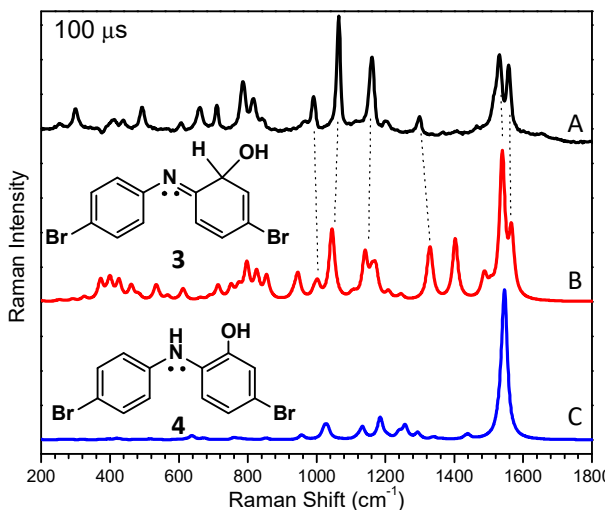

Figure 5. The $\mathrm{ns}^{-\mathrm{TR}^{3}}$ spectrum at $100 \mu \mathrm{s}$ (A) obtained after $266 \mathrm{~nm}$ photoexcitation of $\mathrm{DN}$ in a 1:1 $\mathrm{MeCN}: \mathrm{H}_{2} \mathrm{O}$ is compared with the DFT predicted normal Raman spectrum of intermediate 3 (B) and product $4(\mathrm{C})$.

\section{Materials and Methods}

\subsection{Materials}

The sample of DN was synthesized following the literature procedure [10]. Spectroscopic grade $\mathrm{MeCN}$ were utilized for preparation of the sample solutions. All of the mixed solvent ratios are of volume ratios unless indicated otherwise.

\subsection{Experimental and Computational Methods}

\subsection{1. fs-TA and ns-TA Experiments}

The fs-TA and ns-TA experiments were performed by following the same experimental apparatuses and methods that have been detailed previously [19-21]. In detail, fs-TA measurements were done using a femtosecond regenerative amplified Ti:sapphire laser system (Sarasota, FL, USA), in which the amplifier was seeded with the $120 \mathrm{fs}$ laser pulses from an oscillator laser system. The laser probe pulse was produced by utilizing $\sim 5 \%$ of the amplified $800 \mathrm{~nm}$ laser pulses to generate a white-light continuum (350-800 nm) in a moving $\mathrm{CaF}_{2}$ crystal, then this probe beam was split into two parts before going into the sample. One probe laser beam goes through the sample, while the other probe laser beam goes to the reference spectrometer in order to monitor the fluctuations in the probe beam intensity. For the present experiments, the sample solution was excited by a $267 \mathrm{~nm}$ pump beam (the third harmonic of the fundamental $800 \mathrm{~nm}$ from the regenerative amplifier). The $40 \mathrm{~mL}$ solutions were studied in a flowing $2 \mathrm{~mm}$ path-length cuvette with an absorbance of 1 at $267 \mathrm{~nm}$ throughout the data acquisition.

The ns-TA measurements were conducted using the commercial LP920 laser flash system (Livingston, UK). The fresh sample solutions were excited by a Q-switched Nd:YAG laser (4th harmonic line at $\lambda=266 \mathrm{~nm}$ ). The probe light from a pulsed $450 \mathrm{~W}$ Xenon arc lamp was passed through various optical elements, samples, and a monochromator before being detected by a fast photomultiplier tube and recorded with a TDS 3012C digital signal analyzer). In the kinetics mode, a photomultiplier 
detector or InGaAs PIN detector is used, and the transient signal is acquired using a fast, high resolution oscilloscope. In the spectral mode, an array detector is fitted to the spectrograph exit port to measure a full range of wavelengths simultaneously. Unless specified otherwise, the ns-TA experiments were performed in air saturated solutions and the sample solutions were made up to have an absorbance of 1 at $266 \mathrm{~nm}$.

\subsection{2. $\mathrm{ns}^{-\mathrm{TR}^{3}}$ Experiments}

The ns-TR ${ }^{3}$ experiments have also been previously discussed in detail [21,22]. The pump laser pulse with a wavelength of $266 \mathrm{~nm}$ generated from the fourth harmonic of a Nd:YAG nanosecond pulsed laser, a $416 \mathrm{~nm}$ probe laser pulse produced from the first Stokes hydrogen Raman shifted laser line from the third (355 nm) harmonic, and a $341.5 \mathrm{~nm}$ probe laser pulse produced from the second Stokes hydrogen Raman shifted laser line from the fourth $(266 \mathrm{~nm})$ harmonic were employed in the ns-TR ${ }^{3}$ experiments. The two Nd:YAG lasers were synchronized electronically by a pulse delay generator to control the time delay of pump and probe lasers, and the time delay between the laser pulses was monitored by a fast photodiode and $500 \mathrm{MHz}$ oscilloscope. The time resolution for this ns-TR ${ }^{3}$ experiments was approximately $10 \mathrm{~ns}$. The pump and probe laser beams were lightly focused onto the sampling system, and the Raman light was collected using reflective optics into a spectrometer whose grating dispersed the light onto a liquid nitrogen cooled CCD detector. The spectra in this work were calibrated by the known MeCN solvent's Raman bands with an estimated accuracy of $\left(5 \mathrm{~cm}^{-1}\right)$. The used samples solutions were prepared to have an UV absorption $\sim 1$ at $266 \mathrm{~nm}$ in a $1 \mathrm{~mm}$ path-length cuvette.

\subsubsection{Density Functional Theory Calculations}

The DFT calculations were done employing the B3LYP hybrid functional with a 6-311G(d,p) basis set in PCM solvent mode with selected solvent molecules. No imaginary frequency modes were observed at the stationary states of the optimized structures. Time-dependent density functional theory was used to calculate the excitation energies, oscillator strengths, and the simulation of UV-vis spectra of selected intermediates. A Lorentzian function with a $10 \mathrm{~cm}^{-1}$ band width for the vibrational frequencies and a scaling factor of 0.975 were employed for comparison with experimental results [23,24]. More details could refer to our previous works [19,20]. The Gaussian 09 program suite [25] installed in HKU Research Computing facilities was employed.

\section{Conclusions}

The photochemistry of $\mathrm{DN}$ in $\mathrm{MeCN}$ and near neutral aqueous solutions was investigated by using fs-TA, ns-TA, and ns-TR ${ }^{3}$ spectroscopic methods, and results from DFT calculations were utilized to interpret the data. The formation of 2 was directly observed by fs-TA to take place within about 4 ps in $\mathrm{MeCN}$ and near neutral aqueous solution. Ns-TR ${ }^{3}$ experiments obtained information about the vibrational characteristic of 2 that exhibited a more intense resonance Raman signal than that for seen for 1 because of a halogen electronic effect. Ns-TA and ns-TR ${ }^{3}$ experiments examined the nucleophilic adduct reaction of 2 with $\mathrm{H}_{2} \mathrm{O}$ in a near neutral aqueous solution, and directly probed the formation of intermediate 3 that demonstrated the efficient and diagnostic reaction pathway for 2 with $\mathrm{H}_{2} \mathrm{O}$ when the DN para position is obstructed by the bromine atom. Scheme 2 shows the proposed reaction mechanisms for the photochemistry of $\mathrm{DN}$ in $\mathrm{MeCN}$ and in a near neutral aqueous solution as a summary. We expect that the results here could be useful in helping us understand and design the next time-resolved spectroscopic investigation of the covalent addition and/or other reactions between selected related nitrenium ions and other molecules.

Supplementary Materials: The following are available online, including Figures S1-S5, as well as Cartesian coordinates, total energies, and vibrational zero-point energies from DFT calculations. 
Author Contributions: Conceptualization, L.D., X.L. and D.L.P.; investigation, Z.Y.; synthesis, L.D. and R.Z.; writing-original draft preparation, L.D. and X.L.; writing-review and editing, L.D. and D.L.P.; supervision, D.L.P.

Funding: This research was funded by the National Science Fund of China (21803026) and the Hong Kong Research Grants Council (grants HKU 7035/13P, AoE/P-03/08, SEG HKU/07) and The University of Hong Kong Development Fund 2013-2014 project "New Ultrafast Spectroscopy Experiments for Shared Facilities".

Acknowledgments: The computations were performed using the HKU ITS research computing facilities that are supported in part by the Hong Kong UGC Special Equipment Grant (SEG HKU09).

Conflicts of Interest: The authors declare no conflicts of interest.

\section{References}

1. Miller, E.C.; Lotlikar, P.D.; Miller, J.A.; Butler, B.W.; Irving, C.C.; Hill, J.T. Reactions in vitro of some tissue nucleophiles with the glucuronide of the carcinogen N-hydroxy-2-acetylaminofluorene. Mol. Pharmacol. 1968, 4, 147-154.

2. Miller, E.C.; Miller, J.A. Mechanisms of chemical carcinogenesis: Nature of proximate carcinogens and interactions with macromolecules. Pharmacol. Rev. 1966, 18, 805-838.

3. Poirier, L.A.; Miller, J.A.; Miller, E.C.; Sato, K. N-Benzoyloxy-N-methyl-4-aminoazobenzene: Its Carcinogenic Activity in the Rat and Its Reactions with Proteins and Nucleic Acids and Their Constituents in Vitro. Cancer Res. 1967, 27, 1600-1613.

4. Novak, M.; Kennedy, S.A. Inhibitory effect of DNA structure on the efficiency of reaction of guanosine moieties with a nitrenium ion. J. Phys. Org. Chem. 1998, 11, 71-76. [CrossRef]

5. Novak, M.; Kennedy, S.A. Selective Trapping of $N$-Acetyl-N-(4-biphenylyl)nitrenium and $\mathrm{N}$-Acetyl-N-(2-fluorenyl)nitrenium Ions by 2'-Deoxyguanosine in Aqueous Solution. J. Am. Chem. Soc. 1995, 117, 574-575. [CrossRef]

6. McClelland, R.A.; Ahmad, A.; Dicks, A.P.; Licence, V.E. Spectroscopic Characterization of the Initial C8 Intermediate in the Reaction of the 2-Fluorenylnitrenium Ion with 2'-Deoxyguanosine. J. Am. Chem. Soc. 1999, 121, 3303-3310. [CrossRef]

7. Humphreys, W.G.; Kadlubar, F.F.; Guengerich, F.P. Mechanism of C8 alkylation of guanine residues by activated arylamines: Evidence for initial adduct formation at the N7 position. Proc. Natl. Acad. Sci. USA 1992, 89, 8278-8282. [CrossRef]

8. McClelland, R.A.; Gadosy, T.A.; Ren, D. 1997 Alfred Bader Award Lecture Reactivities of arylnitrenium ions with guanine derivatives and other nucleophiles. Can. J. Chem. 1998, 76, 1327-1337. [CrossRef]

9. Chan, P.Y.; Kwok, W.M.; Lam, S.K.; Chiu, P.; Phillips, D.L. Time-resolved resonance Raman observation of the 2-fluorenylnitrenium ion reaction with guanosine to form a C8 intermediate. J. Am. Chem. Soc. 2005, 127, 8246-8247. [CrossRef]

10. Thomas, S.I.; Falvey, D.E. N,N-di(4-halophenyl)nitrenium ions: Nucleophilic trapping, aromatic substitution, and hydrogen atom transfer. J. Org. Chem. 2007, 72, 4626-4634. [CrossRef]

11. McIlroy, S.; Moran, R.J.; Falvey, D.E. Photogenerated nitrenium ions: A search for triplet-state reactivity in the chemistry of the diphenylnitrenium ion. J. Phys. Chem. A 2000, 104, 11154-11158. [CrossRef]

12. Moran, R.J.; Falvey, D.E. Photogenerated diarylnitrenium ions: Laser flash photolysis and product studies on diphenylnitrenium ion generated from photolysis of 1 -( $N, N$-diphenylamino)pyridinium ions. J. Am. Chem. Soc. 1996, 118, 8965-8966. [CrossRef]

13. Kung, A.C.; McIlroy, S.P.; Falvey, D.E. Diphenylnitrenium ion: Cyclization, electron transfer, and polymerization reactions. J. Org. Chem. 2005, 70, 5283-5290. [CrossRef]

14. Srivastava, S.; Ruane, P.H.; Toscano, J.P.; Sullivan, M.B.; Cramer, C.J.; Chiapperino, D.; Reed, E.C.; Falvey, D.E. Structures of reactive nitrenium ions: Time-resolved infrared laser flash photolysis and computational studies of substituted N-methyl-N-arylnitrenium ions. J. Am. Chem. Soc. 2000, 122, 8271-8278. [CrossRef]

15. Macernis, M.; Kietis, B.P.; Sulskus, J.; Lin, S.H.; Hayashi, M.; Valkunas, L. Triggering the proton transfer by H-bond network. Chem. Phys. Lett. 2008, 466, 223-226. [CrossRef]

16. Kwok, W.M.; Chan, P.Y.; Phillips, D.L. Direct observation of the 2-fluorenylnitrene and 4-methoxyphenylnitrene reactions with water using picosecond Kerr-gated time-resolved resonance Raman spectroscopy. J. Phys. Chem. B 2004, 108, 19068-19075. [CrossRef] 
17. Srivastava, S.; Toscano, J.P.; Moran, R.J.; Falvey, D.E. Experimental confirmation of the iminocyclohexadienyl cation-like structure of arylnitrenium ions: Time-resolved IR studies of diphenylnitrenium ion. J. Am. Chem. Soc. 1997, 119, 11552-11553. [CrossRef]

18. Coates, J. Interpretation of Infrared Spectra, A Practical Approach. In Encyclopedia of Analytical Chemistry; John Wiley \& Sons, Ltd: Hoboken, NJ, USA, 2006.

19. Du, L.; Li, M.-D.; Zhang, Y.; Xue, J.; Zhang, X.; Zhu, R.; Cheng, S.C.; Li, X.; Phillips, D.L. Photoconversion of $\beta$-Lapachone to $\alpha$-Lapachone via a Protonation-Assisted Singlet Excited State Pathway in Aqueous Solution: A Time-Resolved Spectroscopic Study. J. Org. Chem. 2015, 80, 7340-7350. [CrossRef]

20. Du, L.L.; Zhu, R.X.; Xue, J.D.; Du, Y.; Phillips, D.L. Time-resolved spectroscopic and density functional theory investigation of the photochemistry of suprofen. J. Raman. Spectrosc. 2015, 46, 117-125. [CrossRef]

21. Du, L.L.; Zhang, X.T.; Xue, J.D.; Tang, W.J.; Li, M.D.; Lan, X.; Zhu, J.R.; Zhu, R.X.; Weng, Y.X.; Li, Y.L.; et al. Influence of Water in the Photogeneration and Properties of a Bifunctional Quinone Methide. J. Phys. Chem. B 2016, 120, 11132-11141. [CrossRef]

22. Du, L.; Qiu, Y.; Lan, X.; Zhu, R.; Phillips, D.L.; Li, M.-D.; Dutton, A.S.; Winter, A.H. Direct Detection of the Open-Shell Singlet Phenyloxenium Ion: An Atom-Centered Diradical Reacts as an Electrophile. J. Am. Chem. Soc. 2017, 139, 15054-15059. [CrossRef]

23. Scott, A.P.; Radom, L. Harmonic vibrational frequencies: An evaluation of Hartree-Fock, Moller-Plesset, quadratic configuration interaction, density functional theory, and semiempirical scale factors. J. Phys. Chem. 1996, 100, 16502-16513. [CrossRef]

24. Merrick, J.P.; Moran, D.; Radom, L. An evaluation of harmonic vibrational frequency scale factors. J. Phys. Chem. A 2007, 111, 11683-11700. [CrossRef] [PubMed]

25. Frisch, M.J.; Trucks, G.W.; Schlegel, H.B.; Scuseria, G.E.; Robb, M.A.; Cheeseman, J.R.; Scalmani, G.; Barone, V.; Mennucci, B.; Petersson, G.A.; et al. Gaussian 09; Gaussian, Inc.: Wallingford, CT, USA, 2009.

Sample Availability: Samples of the compounds are available from the authors.

(C) 2018 by the authors. Licensee MDPI, Basel, Switzerland. This article is an open access article distributed under the terms and conditions of the Creative Commons Attribution (CC BY) license (http://creativecommons.org/licenses/by/4.0/). 